practical solutions to engaging effectively with these communities. The project is set in an area of high deprivation and high levels of unemployment within the South Asian community. Working in partnership with the PCT and local community organisations the project takes a community development approach to recruit unemployed people from these communities into apprenticeship posts which will give them the skills and qualifications in Health and Social care. As part of their apprenticeship each student is involved in developing shared understanding, new ways of working together as well as breaking down the barriers between the South Asian community and the various statutory and voluntary sector healthcare organisations involved in palliative care.

Results An independent evaluation is being undertaken by the University of Bradford and the results of their interim report are used as the basis for this presentation.

Conclusion The research demonstrates a practical model which can be adapted by any hospice who wants to increase access to hard to reach communities and improve recruitment from similar groups.

\section{P173 HOSPICE APPRENTICE WITH THE SOUTH ASIAN} COMMUNITY

Steve Davison, ${ }^{1}$ Sikander Hussaine, ${ }^{1}$ Vanessa Taylor ${ }^{2}{ }^{1}$ Manorlands Hospice Sue Ryder, West Yorkshire, UK; ${ }^{2}$ University of Bradford, Bradford, UK

10.1136/bmjspcare-2011-000105.173

Presentation aim To explore the implications for hospices of a 3 year DH funded project based at Sue Ryder Manorlands Hospice with the twin aims of

- Increasing the access for specialist Palliative care from the South Asian community

- Achieving the first aim by recruiting 10 unemployed people from the South Asian Community to 12 month apprenticeships with an NVQ in Health and Social care.

Methodology It is recognised nationally that there is a very low uptake of specialist palliative care services from people from various ethnic minority backgrounds and also a significant problem in recruiting skilled healthcare staff from these same communities. Various research studied have identified the problems but little work has been undertaken to find 